\title{
Penyusunan Peraturan Desa Tentang Bale Mediasi Melalui Penyuluhan dan Monitoring Pada Desa Rumak, Kecamatan Kediri, Kabupaten Lombok Barat
}

\author{
Rinda Philona, I Made Suradana, Novita Listyaningrum \\ Fakultas Hukum Universitas 45 Mataram \\ Jalan Imam Bonjol Cakranegara Kota Mataram NTB
}

\section{Article history}

Received: 14-02-2021

Revised: 25-02-2021

Accepted: 14-03-2021

*Corresponding Author: Rinda Philona,

Fakultas Hukum Universitas 45 Mataram, Indonesia;

Email:

rindakhansa@gmail.com
Abstract: This extension and monitoring activity aims to provide knowledge and understanding to the people of Rumak Village about how the basic mechanisms and knowledge in drafting a village regulation, in this case Bale Mediation, is an institution that carries out mediation, guidance and coordination functions in the implementation of mediation in the community in accordance with local wisdom. This counseling also simultaneously monitors conditions or problems that occur in the Rumak Village community which can be resolved through mediation or nonlitigation. This outreach activity was held thanks to the cooperation of various parties, namely: Rumak Village Officials consisting of the government of Village, the Secretary of the Hamlet and Bhabinkamtibmas, the NTB Province Bale Mediation Institute and Law Faculty Lecturers from various existing universities. Extension activities are carried out using the lecture and discussion method. All extension participants followed the series of events well to the end and were very enthusiastic by providing various kinds of questions that often occur. Therefore, it can be concluded that the implementation of this counseling went well and was successful where the material presented could be well absorbed by the Rumak Village officials and they would implement everything to be applied to the Rumak Village community.

Keywords: drafting; village regulations; bale mediation

Abtrak: Kegiatan penyuluhan dan monitoring bertujuan untuk memberikan pengetahuan dan pemahaman kepada masyarakat Desa Rumak tentang bagaimana mekanisme dasar dan pengetahuan dalam menyusun sebuah peraturan desa dalam hal ini tentang Bale Mediasi yang merupakan sebuah lembaga yang menjalankan fungsi mediasi, pembinaan dan koordinasi dalam pelaksanaan mediasi dimasyarakat sesuai dengan kearifan lokal. Penyuluhan ini juga sekaligus memonitoring kondisi atau permasalahan yang terjadi pada masyarakat Desa Rumak yang bisa diselesaikan dengan jalur mediasi atau nonlitigasi. Kegiatan ini terselenggara berkat kerjasama berbagai pihak yaitu : Perangkat Desa Rumak yang terdiri dari Kepala Desa, Sekretaris, Kepala Dusun dan Bhabinkamtibmas, Lembaga Bale Mediasi Provinsi NTB serta Para Dosen Fakultas Hukum dari berbagai universitas yang ada dilombok. Kegiatan dilaksanakan dengan metode ceramah dan diskusi. Seluruh peserta mengikuti rangkaian acara dengan baik sampai selesai dan sangat antusias dengan memberikan berbagai macam pertanyaan yang sering terjadi. Oleh karena itu dapat diambil kesimpulan pelaksanaan peyuluhan ini berjalan dengan baik dan sukses dimana materi yang disampaikan dapat terserap dengan baik oleh para aparatur Desa dan akan mengimplemantasikan segala sesuatunya untuk diaplikasikan pada masyarakat Desa Ruma.

Kata Kunci: Penyusunan;Peraturan Desa; Bale Mediasi 


\section{PENDAHULUAN}

Desa Rumak adalah desa yang berada di kecamatan Kediri, Kabupaten Lombok Barat, Nusa Tenggara Barat. Desa Rumak terdiri dari empat dusun, yaitu Dusun Rumak Timur Utara, Dusun Rumak Timur Selatan, Dusun Rumak Barat Utara dan Dusun Rumak Barat Selatan. Desa ini sangat potensial untuk pengembangan usaha Jasa dan Perdagangan mengingat lokasinya yang sangat strategis berada pada jalur menuju Pelabuhan Laut Lembar dan Bandara Internasional Lombok. (Wikipedia, 2021) Berdasarkan luas wilayah dan masyarakatnya yang cukup besar seringkali terjadi suatu permasalahan baik permasalahan perdata maupun pidana ringan maupun berat, yang mana dalam pelaksanaannya aparatur DesaRumak cukup merasa kewalahan untuk menyelesaikannya. Permasalahan yang terjadi seperti: pembagian warisan yang seringkali menimbulkan konflik antara keluarga, pernikahan dini, permasalahan tanah hibah serta kasus-kasus pidana ringan lainnya yang dapat diselesaikan dengan jalur non litigasi atau dengan metode mediasi. Menyikapi hal ini dari Bale Mediasi Provinsi NTB bekerjasama dengan beberapa Dosen Hukum dari Fakultas Hukum Universitas 45 Mataram dan Fakultas Hukum Muhamadiyah Mataram mengadakan penyuluhan tentang perlunya dibentuk Peraturan Desa tentang Bale Mediasi yang mana telah dibentuk sebelumnya Peraturan Daerah Nomor 9 Tahun 2018 tentang Bale Mediasi sehingga diperlukan turunan pembentukan Peraturan Desa agar dalam pengaplikasiannya bisa sampai pada ranah yang paling dasar yaitu tingkat Desa dan Dusun.

\section{METODE}

Mitra Pelaksana: Acara penyuluhan ini terselenggara atas kerjasama: 1) Perangkat Desa Rumak Lombok Barat, 2). Lembaga Bale Mediasi Provinsi Nusa Tenggara Barat 3).Dosen-Dosen Fakultas Hukum Universitas 45 Mataram dan Universitas Muhamadiyah Mataram.

Peserta: Peserta aktif kegiatan penyuluhan hukum ini adalah: Perangkat Desa Rumak seperti: Kepala Desa Rumak, Sekretaris, Para Kepala Dusun, Ketua Taruna, Bhabinkambtibmas, beserta unsur-unsur perwakilan organisasi Desa Rumak.

Mekanisme Persiapan Acara: Kegiatan Penyuluhan hukum ini merupakan inisiasi dari Lembaga Bale Mediasi Provinsi Nusa Tenggara Barat yang bertujuan guna terbentuknya Peraturan Desa tentang Bale Mediasi. Oleh Karena itu Bale Mediasi Provinsi NTB menggandeng beberapa unsur Dosen dan aparatur Desa guna mengadakan penyuluhan dan monitoring ini sehingga dapat terwujudnya Peraturan Desa tentang Bale Mediasi.

Tempat dan Waktu : Kegiatan penyuluhan ini berlangsung pada hari kamis tanggal 10 Desember 2020 pada pukul 09.00 wita s/d selesai dan bertempat di : Kantor Desa Rumak Lombok Barat

Metode Pelaksanaan: Metode yang dipergunakan dalam kegiatan penyuluhan dan Monitoring ini adalah metode ceramah, diskusi dan tanya jawab. 


\section{HASIL DAN PEMBAHASAN}

\section{Realisasi Pemecahan Masalah}

Dewasa ini Negara dihadapkan dengan semakin banyaknya persoalan yang terjadi karena kemajemukan manusia sehingga timbulah bermacam kejadian dan sengketa. Sengketa adalah merupakan suatu fenomena yang selalu kita jumpai pada setiap masyarakat yang masih bercorak tradisonal, masyarakat modern bahkan masyarakat pasca modern yang mempunyai kaitan dengan hukum yang berlaku dalam masyarakat yang bersangkutan atau lebih tepatnya dengan hukum sebagaimana banyak mendapat perhatian dari para pengkaji hukum dan masyarakat. Telah terbentuk Lembaga-Lembaga permanen yang bergerak dalam bidang hukum dan bertugas untuk melindungi masyarakat dari kejahatan dan sengketa yang ada, lembaga tersebut adalah: Kepolisian, Kejaksaan dan Pengadilan (Abdurahman, 2008). Persoalan-persoalan yang terjadi seiring berjalannya waktu semakin banyak baik dari kasus perdata maupun kasus pidana sehingga terkadang lembaga-lembaga hukum yang ada merasa kewalahan dalam penyelesaiannya, berdasarkan hal tersebut maka upaya lain yang dilakukan adalah dengan jalur non litigasi atau penyelesaian sengketa diluar pengadilan yaitu dengan jalan Mediasi. Mediasi adalah penyelesaian sengketa melalui proses perundingan musyawarah mufakat untuk memperoleh kesepakatan para pihak dengan bantuan mediator. Mediasi ini dirasakan banyak manfaatnya bagi banyak pihak yang berperkara karna prosesnya lebih mudah dan tujuan dari mediasi adalah kesepakatan antara para pihak atau win win solution. Cristopher W Moore mengemukakan pandangannya mengenai kekuatan mediasi yaitu: "jika potensi pengaruh kekuatan dari pihak-pihak dikembangkan dengan baik, persamaan yang fair dalam kekuatan tersebut dan disadari oleh pihak yang bersengketa, tugas mediator untuk mengakses pengaruh salah satu pihak ke pihak lain secara efektif akan menghasilkan keputusan/kepuasan bersama para pihak (Made Sukadana, 2012).

Berangkat dari hal tersebut maka di Nusa Tenggara Barat dibentuk sebuah lembaga mediasi non struktural yang dinamakan Bale Mediasi. Bale Mediasi adalah lembaga yang menjalankan fungsi mediasi, pembinaan dan koordinasi dalam pelaksanaan mediasi dimasyarakat sesuai dengan kearifan lokal. Bale Mediasi bukan merupakan bagian dari peradilan negara melainkan lembaga yang menyelesaikan sengketa di luar pengadilan. Bale Mediasi telah diatur dalam Peraturan Daerah Nomor 9 Tahun 2018 tentang Bale Mediasi. Dalam pembentukkan Bale Mediasi diperlukan Susunan Organisasi yang terdiri atas: Pembina, Pengarah, Penanggung Jawab dan Pelaksana Harian. Bale mediasi menangani sengketa sengketa dalam bidang perdata dan tindak pidana ringan. Peran Bale Mediasi disini menyelesaikan sengketa di masyarakat dengan cara mediasi melalui prinsip musyawarah mufakat di luar pengadilan. Pembentukan Bale Mediasi bertujuan untuk: (Berdasarkan Pasal 3 Perda No.9 Tahun 2018):

a. pengakuan pemerintah sebagai wujud perlindungan, penghormatan dan pemberdayaan terhadap keberadaan lembaga adat dalam menjalankan fungsi mediasi;

b. mencegah dan meredam konflik-konflik atau sengketa di masyarakat secara lebih dini;

c. terselenggaranya penyelesaian sengketa di masyarakat melalui mediasi demi terciptanya suasana yang rukun, tertib dan harmonis. 
Adapun Prosedur Penyelesaian Sengketa Di Bale Mediasi adalah:

A. Penyampaian Permohonan Mediasi ( Pasal 18-19 Perda No.9 Tahun 2018) :

1. Setiap orang dan/atau masyarakat yang dirugikan hak-hak keperdataannya oleh orang lain dan/atau masyarakat lainnya dapat mengajukan permohonan kepada Bale Mediasi untuk dimediasi.

2. Setiap orang dan/atau masyarakat yang menjadi korban tindak pidana/perbuatan pidana dapat mengajukan permohonan kepada Bale Mediasi untuk dimediasi.

3. Permohonan harus mencantumkan secara jelas tentang keinginan untuk menyelesaikan sengketa dengan cara mediasi di Bale Mediasi.

4. Bale Mediasi melakukan registrasi pada setiap permohonan yangmasuk ke dalam buku register perkara.

5. Paling lama 3 (tiga) hari terhitung sejak permohonan didaftarkan, Bale Mediasi menyampaikan jawaban atas permohonan kepada pihak pemohon.

B. Hasil Kesepakatan Perdamaian (Pasal 20 Perda Nomor 9 Tahun 2018 ) :

1. Mediator merumuskan kesepakatan perdamaian secara tertulis.

2. Kesepakatan perdamaian tidak memuat ketentuan yang :

a. bertentangan dengan hukum, ketertiban umum dan adatistiadat masyarakat;

b. merugikan pihak ketiga; atau

c. tidak dapat dilaksanakan.

3. Hasil kesepakatan perdamaian dituangkan ke dalam Akta Perdamaian yang ditandatangani para pihak, mediator dan diketahui oleh Ketua Bale Mediasi yang bersifat final dan mengikat.

4. Akta Perdamaian didaftarkan ke Pengadilan Negeri setempat untuk mendapatkan keputusan yang bersifat eksekutorial

C. Pendanaan ( Pasal 27 Perda Nomor 6 Tahun 2018 ) :

1. Pendanaan atas pengelolaan Bale Mediasi bersumber dari:

a. Anggaran Pendapatan dan Belanja Daerah (APBD);

b. Sumber lain yang sah dan tidak mengikat.

2. Pendanaan dari APBD diperuntukkan untuk pembayaran gaji/upah pengurus Bale Mediasi.

Berdasarkan hal hal diatas tentang Bale Mediasi yang mana perlu dibentuk sampai akar rumput paling dasar yaitu pada tingkat desa karna dari dusun dan desalah banyak masyarakat ini berasal dan persolan-persoalan yang terjadi harus diselesaikan dari tingkat desa. Oleh karena itu penyuluhan ini dilaksanakan guna memberi pemahaman dasar tentang Bale Mediasi dan Pembentukan Peraturan Desa oleh Desa Rumak.

\section{Tahapan Penyusunan Peraturan Desa:}

1. .Kajian/identifikasi permasalahan;

2. Penyusunan Kajian Akademik;

3. Penyusunan Draft Peraturan Desa;

4. Konsultasi Publik ( partisipasi masyarakat);

5. Penyempurnaan Draft Perdes;

6. Pembahasan antara Pemdes dan BPD (persetujuan bersama);

7. Penetapan; 
8. Pengundangan; dan

9. Sosialisasi kepada masyarakat;

Berdasarkan tahapan penyusunan Peraturan Desa dapat dijelaskan:

1. Tahapan Identifikasi Masalah: dilakukan dengan mengkaji aspek filosofis, mengidentifikasi permasalahan (perilaku bermasalah pemegang peran, badan pelaksana) merupakan kajian dari aspek empiris-sosiologis selanjutnya dilakukan kajian aspek yuridis, peraturan perundangundangan sebagai dasar hukum pembentukan perdes.

2. Penyusunan draft Perdes berdasarkan Naskah Akademik :

1. Penamaan/judul

2. Konsideran

2. Ketentuan Umum

3. Materi pokok yang diatur

4. Ketentuan Sanksi (kalau diperlukan)

5. Ketentuan Peralihan (kalau diperlukan)

6. Ketentuan Penutup

3. Tahapan selanjutnya:

a. Public Hearing (konsultasi Publik) dimaksudkan untuk menjaring masukan dari masyarakat terhadap Draft Perdes.

b. Masyarakat yang diundang, yaitu yang kepentingannya diatur dalam perdes, akademisi,

c. Masukan masyarakat sebagai bahan masukan untuk penyempurnaan rancangan perdes.

4. Pembahasan raperdes dengan Kepaa Desa dan BPD

a. Rapat bersama antara Kepala Desa dan BPD.

b. Pembahasan bersama dapat mengundang Tim Ahli.

c. Persetujuan bersama Kepala Desa dan BPD.

5. Penetapan adalah penantanganan Raperdes oleh Kepala Desa agar Perdes memiliki kekuatan Hukum dan kekuatan berlaku.

6. Pengundangan oleh Sekdes dalam Lembaran Desa agar Perdes tersebut mempunyai kekuatan mengikat bagi semua stakeholders.

7. Sosialisasi Kepada Masyarakat: Sosialisasi dimaksudkan agar masyarakat dan semua stakeholders yang diatur oleh Perdes tersebut mengetahuinya, orang akan taat pada peraturan apabila dia terlebih dahulu mengetahui dan memahami isinya yang mengatur hak dan kewajibannya.

Berdasarkan materi pembahasan yang dipaparkan diatas bahwa dalam pelaksanaan penyuluhan hukum dan monitoring yang dihadiri oleh berbagai perangkat Desa Rumak ini begitu banyak apresiasi selama kegiatan berlangsung dimana pertanyaan-pertanyaan yang mereka alami selama dilapangan atau langsung berhadapan dengan masyarakat Desa Rumak yang memiliki permasalahan berbeda beda, seperti dicontohkan oleh seorang Kepala Dusun yang sering menghadapi permasalahan masyarakat mengenai perkawinan dini ataupun sengketa tanah yang terkadang mereka menginginkan penyelesaian permasalahan dengan cara berakhir dimeja hijau dan merasa mediasi bukanlah cara penyelesaian masalah. Akan tetapi setelah kami menyampaiakan materi secara detail tentang bergunanya bale mediasi para perangkat desa lebih memiliki kepercayaan diri dan akan menyampaikan materi yang kami sampaikan kepada masyarakat desa rumak juga. 
Faktor pendukung dalam penyuluhan hukum dan monitoring ini:

1. Tempat yang disediakan untuk melaksanakan penyuluhan hukum sangat strategis dan memadai

2. Antusias dan kehadiran berbagai perangkat Desa Rumak memenuhi undangan penyuluhan hukum dan monitoring

3. Para penyuluh yang menyampaikan materi dengan lugas sehingga penyuluhan hukum ini berlangsung dengan hidup dan tujuan yang ingin dicapai tersampaikan.

Faktor Penghambat dalam penyuluhan dan monitoring ini:

1. Waktu yang disediakan cukup terbatas sehingga berbagai pertanyaan yang tersedia tidak bisa terjawab secara keseluruhan.

2. Kurangnya sarana tekhnologi dalam penyampaian materi seperti LCD.

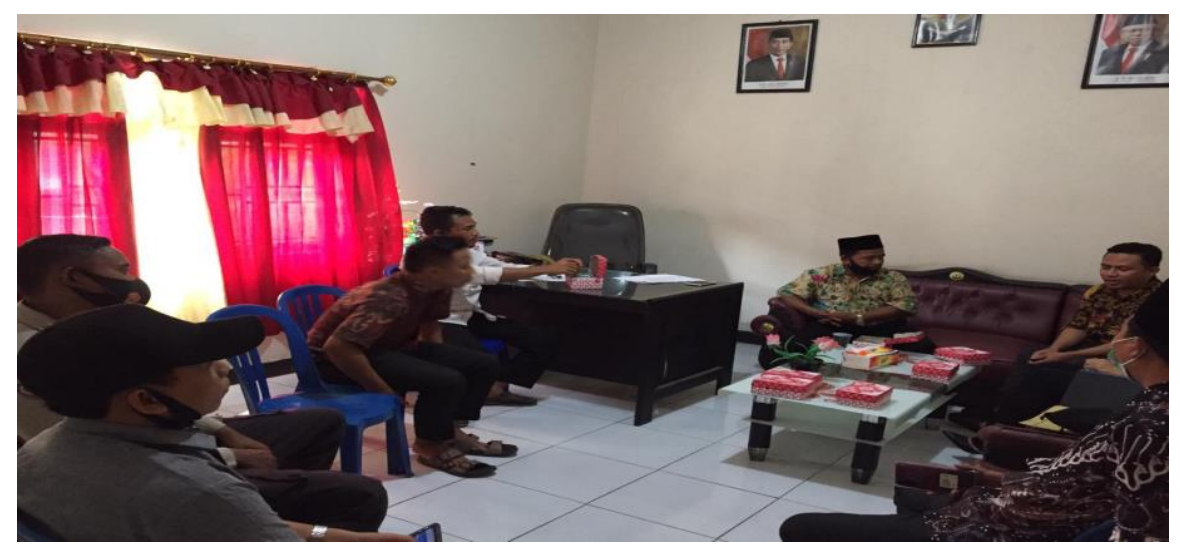

Diskusi bersama Aparatur Desa Rumak dengan Peyuluh.

\section{KESIMPULAN DAN SARAN}

Berdasarkan kegiatan penyuluhan hukum dan monitoring dilaksanakan di Desa Rumak membawa dampak positif dimana masyarakat jadi memiliki pengetahuan dan pemahaman dalam penyusunan Peraturan Desa dan mengetahui secara lebih jelas tentang Bale Mediasi dan perlunya dibentuk Peraturan Desa tentang Bale Mediasi ditiap Desa guna memberi payung hukum dan pembentukan lembaga Bale Mediasi ini diharapkan dapat berkontribusi besar dalam menyelesaikan permasalahan masyarakat khusunya dalam sengketa perdata dan pidana ringan.

\section{Ucapan Terima Kasih}

Sesuai dengan pelaksanaan kegiatan penyuluhan hukum ini dilaksanakan kami ingin mengucapkan rasa terimakasih kepada : Lembaga Bale Mediasi Provinsi NTB sebagai pihak penyelenggara dan promotor dari kegiatan ini, selain daripada itu kami mengucapakn rasa terimakasih sebesar besarnya kepada Kepala desa Rumak beserta jajarannya yang mendukung kegiatan ini berlangsung serta memberikan waktu dan tempat bagi susksesnya kegiatan penyuluhan dan monitoring ini. 


\section{DAFTAR PUSTAKA}

Abdurahman, Penyelesaian Sengketa Melalui Mediasi Pengadilan dan Mediasi Alternatif Penyelesaian Sengketa Dalam Refleksi Dinamika Hukum,Rangkaian Pemikiran Dalam Dekade Terakhir, Analisis Komprehensif Tentang Hukum Oleh 63 Akademisi Dan Praktisi Hukum, Perum Percetakan Negara Republik Indonesia, Jakarta, 2008, cet ke-1

I Made Sukadana, Mediasi Peradilan, Prestasi Pustaka, Jakarta: 2012.

Peraturan Desa Nomor 9 Tahun 2018 tentang Bale Mediasi

Wikipedia.org Rumak, Kediri, Lombok Barat-Wikipedia Bahasa Indonesia, id. 